\title{
Phototherapy as a Treatment for Uremic Pruritus - A Review
}

\author{
Amrit Thakur $^{1}$, Soham Chaudhari ${ }^{2}$, Prakash Chaudhari ${ }^{3}$ and Magendra Thakur ${ }^{4}$ \\ ${ }^{1}$ Danbury Hospital, Department of Medical Education \& Research, Danbury, CT, USA \\ ${ }^{2}$ Palisades Medical Center, North Bergen, NJ, USA \\ ${ }^{3}$ Associated Pathologists Chartered, Las Vegas, NV, USA \\ ${ }^{4}$ St. Lawrence Pulmonology, Potsdam, NY, USA
}

“Corresponding author: Soham Chaudhari, Palisades Medical Center, 7600 River Road, North Bergen, NJ 07047, USA, Tel: (702) 267-8393; Fax: (702) 361-4747; Email: s.chaudhari14@gmail.com

Rec date: July 21, 2015 Acc date: August 18, 2015 Pub date: August 24, 2015

Copyright: (C) 2015 Thakur A, et al. This is an open-access article distributed under the terms of the Creative Commons Attribution License, which permits unrestricted use, distribution, and reproduction in any medium, provided the original author and source are credited.

\begin{abstract}
Generalized Pruritus (GP) is chronic itch that occurs without any associated diagnosable skin diseases or primary skin lesions. Uremic pruritus (UP), also known as Chronic Kidney Disease-associated pruritus (CKD-aP), is the most common cause of GP and is a debilitating symptom in patients with end-stage renal disease. Topical therapy is often inadequate; thus, providing additional therapeutic options becomes essential for the successful primary care physician. Phototherapy is a proven method for the management of many pruritic disorders, including uremic pruritus (UP).
\end{abstract}

Objective: This review aims to give an update on the use of phototherapy for managing UP to establish it within the spectrum of therapeutic options. The pathogenesis of UP and the mechanism of action of phototherapy in treating UP were also reviewed.

Methods: A thorough literature search of the PubMed database was conducted to identify studies that examined a variety of phototherapy methods in UP.

Results: UP causes a microinflammatory state with changes in cutaneous nociceptive endings. A circulating substance responsible for pruritus is annihilated through the apoptotic actions of phototherapy. BB-UVB is the preferred modality to decrease UP.

Conclusion: Phototherapy is a safe and beneficial option when other measures fail to control UP.

Keywords: Phototherapy; Pruritus; Uremic pruritus; Chronic Kidney Disease-associated pruritus

\section{Introduction}

GP is chronic itch that occurs without any associated diagnosable skin diseases or primary skin lesions. Although frequently idiopathic, it can be secondary to neurologic disorders, chronic renal failure, cholestasis, systemic infections, malignancies, and endocrine disorders. A judicious history, thorough physical examination, and suitable laboratory investigation must be performed to elucidate the cause. Systemic disease has been implicated in up to $20 \%$ of patients with GP [1]. Special emphasis should be placed on drug exposure, travel history, environmental irritants, lifestyle, extra-cutaneous symptoms, and prior hospitalizations. Initial laboratory tests may include complete blood count, liver and renal function tests, serum glucose, iron, ferritin, thyroid function tests, erythrocyte sedimentation rate, protein electrophoresis, and urinalysis. Many cases of GP begin in a localized area, and phototherapy can often lead to cessation of generalized itch and reveal a previously localized itch. Generalization can be caused by a lowering of itch threshold on other body parts through a combination of neurologic and/or psychological mechanisms.
Those with a negative workup for GP fall into idiopathic pruritus (IP). In those over the age of 65 , this form of idiopathic itch is often dubbed senile pruritus or Willan's itch as it is often associated with dry skin [2]. The stratum corneum thickens with age and has decreased kertohyaline granules. Elderly patients with dry skin have decreased amount of surface lipids which impair the stratum corneum's ability to hold water [3]. Clearance of debris from the dermis also decreases, along with sweat and sebum production and vascular response to histamine. Xerosis was found to be proportional to the degree of itch with increased intracorneal cohesion and no difference in response to intradermal histamine [4].

End-stage renal disease (ESRD) is defined as progressive and irreversible kidney dysfunction that lasts longer than 3 months [5]. An estimated $50-100 \%$ of patients with ESRD have at least one associated cutaneous change $[6,7]$. These include pigmentary disorders, pruritus, xerosis, acquired ichthyosis, half-and-half nail, acquired perforating dermatosis, calciphylaxis, bullous dermatoses, and fibrosing dermopathy of uremia [5]. Uremic pruritus (UP), also known as Chronic Kidney Disease-associated pruritus (CKD-aP), is a debilitating symptom in patients with ESRD. Of all the systemic disorders linked to pruritus, uremia is the most common [8]. Its prevalence varies from $15 \%$ to $90 \%$ and has been found as the most common symptom experienced by patients on hemodialysis when 
compared to other cutaneous manifestations [9-11]. 15-49\% of those with chronic renal failure (CRF) and $90 \%$ receiving dialysis have uremic pruritus (UP) [12]. Up to 50\% of UP patients complain about generalized pruritus $[8,13]$. In the remaining, UP affects predominantly back, face, and shunt-arm [10]. Nearly half of hemodialysis patients experience continued pruritus, whereas for others, it occurs occasionally with episodes of exacerbation [14]. Clinically, UP skin resembles that of hemodialysis patients without pruritus, dry and scaly. No primary skin lesions are seen; however, chronic excoriations, linear crusts, and ulcerations can evolve. Pruritus of hemodialysis and that of peritoneal dialysis occur in similar a frequency $[15,16]$. Although the incidence of pruritus increases as renal function deteriorates, it does not improve with dialysis and is an independent marker of mortality at 3 years for those on hemodialysis. [17]. The severity of UP is associated with the duration of dialysis and xerosis. Unfortunately, the prevalence and burden of pruritus in endstage renal disease (ESRD) is often underestimated by nephrologists [18], even though it is perceived by patients as a severe and distressing symptom of renal failure [19]. With symptoms lasting for months to years, its chronic nature is an independent predictor of poor quality of life with severe sleep disturbances $[16,20,21]$. It is postulated that periods of inactivity at night and during dialysis sessions exacerbates pruritus $[10,22]$. UP is a major cause of distress to patients and has a significant impact on quality of life. Common treatments for UP include antihistamines, steroids, emollients, and charcoal [23]. However, Topical therapy is often inadequate in controlling pruritus. Therefore, providing additional therapeutic options becomes essential. While there have been some reports of effective treatment with serotonin antagonists, selective serotonin reuptake inhibitors, mast cell stabilizers, leukotriene receptor antagonists, nicotinamide, and opioid receptor antagonists, the side effects of these medications cannot be easily overlooked [24].

Phototherapy is a safe and efficacious management modality which decreases pruritus and can be used across age groups [25]. Ultravioletbased therapy (phototherapy and photochemotherapy) [26] can provide relief for UP patients without many of the risks and adverse effects of systemic medications. UVB (290-320 nm) and UVA (320-400 nm) are implemented in UV-based therapy. Broadband UVB (BB-UVB) and broadband UVA (BB-UVA) use a light source covering their entire spectrum. Narrowband UVB (NB-UVB) uses 311-313 nm and UVA1 uses $340-400 \mathrm{~nm}$ with a peak at $365 \mathrm{~nm}$. UVA1 can be administered at high dose (HD-UVA1) $\left(130 \mathrm{~J} / \mathrm{cm}^{2}\right)$, medium dose (MD-UVA1) $\left(50 \mathrm{~J} / \mathrm{cm}^{2}\right)$, and low dose (LD-UVA1) $\left(20 \mathrm{~J} / \mathrm{cm}^{2}\right)$. Monochromatic Excimer Laser (MEL) $(308 \mathrm{~nm})$ is a more targeted phototherapy device which delivers $308 \mathrm{~nm}$ UVB to a localized area and can expand treatment options by sparing unaffected areas. This review article focuses on the efficacy of these forms of phototherapy to treat UP.

\section{Methods}

For this systematic review we concentrated on the therapeutic role of phototherapy for UP. The computerized bibliographic database PubMed was used to conduct a search for English articles from inception to August of 2014. Research articles of randomized controlled trials (RCT), open prospective studies, pilot studies, and retrospective observations on NB-UVB, BB-UVB, UVA, PUVA, and MEL were included. The following key words were used: "phototherapy pruritus, and phototherapy uremic pruritus." Based on the keywords chosen, 178 articles were revealed. After screening title and abstract, those studies in which phototherapy was not used as a treatment for the chosen disease processes were excluded. Reference lists in review articles were also searched. Abstracts only and duplicates were excluded. This left 58 articles for the screening phase. These records were then assessed for eligibility, excluding other modes of treatment as primary analysis, thereby leaving 12 studies in the final analysis. Relevant data including study design, number of participants, duration of treatment, cumulative phototherapy dosing, adverse effects, and clinical outcome were retrieved from the articles and formulated into spreadsheet databases. When specific pruritus assessment scales were mentioned, we cited them in the results. If no particular assessment scale was used, extent of disease, sleep improvement, and remission were evaluated. Because pruritus is the main symptom of these disorders, the above criteria may be considered synonymous to the resolution of pruritus.

\section{Results}

\section{NB-UVB}

Forty-nine percent of the GP patients treated with NB-UVB resulted in moderate to significant improvement [27]. A study conducted by Seckin compared UP to IP [28]. 68\% of those with IP showed greater than $50 \%$ improvement with a $61 \%$ remission rate on a 6 month average follow-up. $60 \%$ in the UP group showed greater than $50 \%$ improvement with $66.7 \%$ recurrence on follow-up. Although remission after a single course of NB-UVB therapy is not prolonged, $54.2 \%$ in the UP group and $67.9 \%$ in the IP group had a change in visual analog score (VAS). Thus, NB-UVB can be considered as a valuable alternative treatment, even though long term cure is not possible. An open pilot study evaluated pruritus using the VAS and a detailed cumulative score (DCS) and found $70.8 \%$ decrease on the VAS scale and a $71.8 \%$ decrease on the DCS $[29,30] .43 \%$ were in remission 6 months after completing treatment, with 57\% having a recurrence of pruritus on average within 2.5 months. A more recent single-blinded study noted comparable and significant reduction of pruritus intensity in patients treated with both NB-UVB and control during the course of phototherapy and follow-up [26,31]. While the NB-UVB group showed a significant improvement in the involved body surface area affected by pruritus $(\mathrm{p}=0.006)$ and had lower pruritus intensity scores at certain time points, the beneficial effects were marginal comparatively.

\section{BB-UVB}

BB-UVB phototherapy was first described to be useful for achieving a reduction in UP in the late 70's [32]. Ninety percent of patients in the BB-UVB arm responded and $80 \%$ remained free of pruritus on an average of 7 months follow-up. The UVA arm did not experience an improvement in itch intensity and was considered placebo, as proven initially by Taylor et al., an additional study done comparing BB-UVB to placebo found BB-UVB beneficial in decreasing pruritus [33]. One crossover study found BB-UVB and UVA to be equal to placebo, however this study did not have an intervening washout period and therefore the placebo rate can be enhanced, consequently diminishing the therapeutic significance of BB-UVB [34]. Berne et al reported a decrease in epidermal vitamin A content in a study with $10 \mathrm{UP}$ patients treated with whole-body UVA and BB-UVB [35]. Epidermal retinal concentrations were returned to normal after 12 sessions of phototherapy, and 70\% reported relief from pruritus [36]. 
Citation: Thakur A, Chaudhari S, Chaudhari P, Thakur M (2015) Phototherapy as a Treatment for Uremic Pruritus - A Review. Gen Med (Los Angel) 3: 202. doi:10.4172/2327-5146.1000202

Page 3 of 7

A study comparing half-body BB-UVB to whole-body treatments with varying dosimetry, found a reduction in pruritus in eighty-four percent of patients treated with whole-body BB-UVB, with $29 \%$ not relapsing on an average of 10 month follow up [37]. Because patients did not detect a difference in the degree of pruritus between the halfbody BB-UVB and placebo side, BB-UVB phototherapy was concluded to exert a systemic effect on UP secondary to the generalized response. The more intensive schedules accelerated the response temporarily, but it did not increase the percentage of patients who responded. In addition, the beneficial effects of UV exposure were only experienced after a lag time of 2 weeks in some patients. In another study, $80 \%$ of patients responded with complete relief of itching when treated with BB-UVB [38]. Twenty-five-percentage of these claimed relief everywhere except for the palms and soles. All patients in this study had relief at least one month after therapy was discontinued with $60 \%$ maintaining relief for at least six months. Cohen et al reported that $57 \%$ of a series of pruritic patients experienced relief after BB-UVB therapy with a decrease in dermal mast-cell counts accompanying improvement in VAS scores [39]. Finally, a case report by Hsu et al has found BB-UVB more effective in decreasing pruritus in UP than NB-UVB (Table 1) [40].

\begin{tabular}{|c|c|c|c|c|}
\hline Reference, type of study & Participants (n) & Treatment Regimen & Cumulative Dose $\left(\mathrm{J} / \mathrm{cm}^{2}\right)$ & Pruritus Outcomes \\
\hline & & & NB-UVB & \\
\hline Samson Yashar RCS [27] & 6 & 33 irradiations & NB-UVB: 52 & $\begin{array}{l}33 \% \text { had significant improvement ( } 66-100 \% \text { resolution } \\
\text { of lesions and/or reduction of pruritus intensity) }\end{array}$ \\
\hline Seckin [28] RCT & $\begin{array}{l}\text { UP-22 } \\
\text { IP-22 }\end{array}$ & $\begin{array}{l}3 \mathrm{x} / \mathrm{wk} \text { for } 22 \\
\text { irradiations }\end{array}$ & $\begin{array}{l}\text { NB-UVB for UP: } 24.54 \\
\text { NB-UVB for IP: } 20.801\end{array}$ & $\begin{array}{l}\text { UP: } 60 \% \text { had }>50 \% \text { improvement } \\
\text { IP: } 68 \% \text { had }>50 \% \text { improvement }\end{array}$ \\
\hline Ada [29] RCT & 10 & $3 x / w k$ for 6 wks & NB-UVB: NR & $70.8 \%$ decrease with $43 \%$ in remission after 6 months \\
\hline Ko [31] RCT & 21 & $3 x / w k$ for 6 wks & $\begin{array}{l}\text { NB-UVB: NR } \\
\text { UVA: } 1-6\end{array}$ & NB-UVB=UVA \\
\hline & & & BB-UVB & \\
\hline Gilchrest [32] RCT & 18 & $2 \mathrm{x} / \mathrm{wk}$ for $4 \mathrm{wks}$ & $\begin{array}{l}\text { BB-UVB: NR } \\
\text { UVA (placebo): NR }\end{array}$ & $90 \%$ had decreased pruritus \\
\hline Gilchrest [37] RCT BCS & $\begin{array}{l}\text { BB-UVB and UVA: } 7 \\
\text { BB-UVB: } 38 \\
\text { 1/wk for } 6 \text { wks: } 8 \\
\text { 3/wk for } 2 \text { wks: } 12 \\
\text { 2/wk for } 4 \text { wks: } 18\end{array}$ & $\begin{array}{l}\text { BB-UVB and UVA: } \\
\text { 2x/wk for } 4 \text { wks }\end{array}$ & $\begin{array}{l}\text { BB-UVB: NR } \\
\text { Whole body BB-UVB: NR } \\
\text { UVA: NR }\end{array}$ & $\begin{array}{l}\text { BB-UVB and UVA: decrease from severe to moderate } \\
\text { BB-UVB: } 38 \\
75 \% \text { responded } \\
66 \% \text { responded } \\
83 \% \text { responded }\end{array}$ \\
\hline Blachley [34] RCS & $\begin{array}{l}\text { BB-UVB: } 9 \\
\text { UVA:8 }\end{array}$ & $3 x / w k$ for 2 wks & $\begin{array}{l}\text { BB-UVB: NR } \\
\text { UVA: NR }\end{array}$ & BB-UVB > UVA \\
\hline Simpson [35] CoS & 20 & $2 \mathrm{x} / \mathrm{wk}$ for $4 \mathrm{wks}$ & $\begin{array}{l}\text { BB-UVB: NR } \\
\text { UVA: NR }\end{array}$ & $B B-U V B=U V A$ \\
\hline Berne [36] RCT & 10 & 12 irradiations & $\begin{array}{l}\text { BB-UVB: } 7.9 \\
\text { UVA: } 1.3\end{array}$ & $70 \%$ had relief \\
\hline Schultz [38] RCT & 10 & $2-3 \mathrm{x} / \mathrm{wk}$ & BB-UVB: NR & $80 \%$ had complete relief \\
\hline Cohen [39] RCT & 14 & NR & BB-UVB: NR & $\begin{array}{l}57 \% \text { had objective benefit, } 100 \% \text { had decreased itch } \\
\text { intensity }\end{array}$ \\
\hline Hsu [40] CR & 1 & 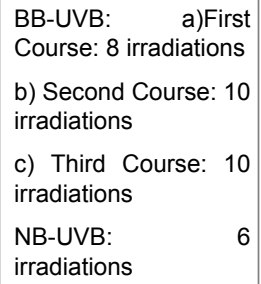 & $\begin{array}{l}\text { First course: } 0.12 \\
\text { Second Course: } 0.23 \\
\text { Third Course: } 0.76 \\
\text { NB-UVB: } 2\end{array}$ & $\begin{array}{l}\text { BB-UVB }>\text { NB-UVB } \\
\text { Cumulative dose of BB-UVB for a good response } \\
\text { increases with repeated treatment }\end{array}$ \\
\hline
\end{tabular}

Table 1: Phototherapy for treatment of uremic pruritus. 


\section{Discussion}

Bernhard classified itch into dermatologic, systemic, neurogenic, psychogenic, mixed, and other categories [41]. While this can help determine the etiology to address management options, the inability to quantify pruritus remains a significant barrier to evolving understanding. Because objective measurements of pruritus are lacking, it is difficult to adequately assess and compare treatments until a uniform, consistent, and reliable scale of evaluating pruritus and scratching exists. Nonetheless, based on current methodologies which involve subjective evaluations, we have attempted to compare the different forms of phototherapy in treating pruritus.

\section{Pathogenesis of itch}

Localized itch involves alpha-delta fibers whereas diffuse, generalized itch is transmitted through dermal unmyelinated c-fibers. Both of these nociceptive fibers travel to the dorsal horn of the spinal cord which is then processed by the cerebral cortex through the spinothalmic tract [42]. They have a slow conduction velocity and innervate large areas of the skin [43]. Dry skin and disruption of the skin barrier can induce keratinocytes to release pruritogenic substances [44]. Nerve fibers typically end at the dermal-epidermal junction, although some project into the epidermis [45]. Itch receptors, formed mostly by keratinocytes, respond to pruritogens, such as histamine, proteases, growth factors, neuropeptides, cytokines, and opioids [46,47] (Figure 1). They are found only in skin, mucus membranes, and cornea [48] Substance P (SubP) and calcitonin generelated peptide (CGRP) are the most studied neurotransmitters and have both central and peripheral activity [49,50]. Allokinesis, the perception on non-pruritic stimuli as pruritic, is due to central sensitization. This explains the intense pruritus $\mathrm{AD}$ patients experience in response to sweat or sudden changes in ambient temperature.

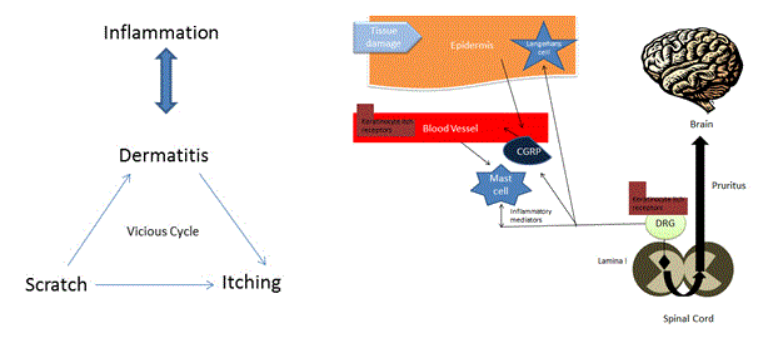

Figure 1: Pruritus.

Mast cells produce two proteinases, tryptase and chymase. Tryptase activates $\mathrm{C}$ fibers and thus stimulates the sensation of itch. It also triggers the release of SubP which not only causes pruritus but also evokes further mast cell activation. Increased levels of tryptase were observed in patients with UP [51].

The sensations of pain and itch are carried by different C-fibers. Frequency of the stimulus can modulate the magnitude of itch, but does not change the quality of itch into pain. Histamine-induced itch activates some motor areas, suggesting a neuronal association between itch and scratching [52]. Scratching and vibration are transmitted by larger A-beta fibers which inhibit itch signals on the slower C-fibers [53]. While pain causes one to avoid a motor response, itch causes a stimulatory motor response. Painful stimuli can inhibit itch as observed in pruritic patients who only stop scratching once skin lesions begin bleeding and become painful. Itch and pain share the same cortical brain areas, but have different patterns of activation; itch has a weaker activation of somatosensory cortices with a stronger activation of ipsilateral motor areas as compared with pain processing $[54,55]$.

\section{Pathogenesis of UP and mechanism of action for phototherapy in UP}

The term "uremic pruritus" is not apt because UP does not result from an increase in serum urea levels. Although the pathogenesis of UP is not completely understood, it is known to present with dystrophic neurotrophic changes in cutaneous nociceptor nerve endings, with a "microinflammatory" state of increased Th1 markers, chemokines, and Interleukin (IL)-6 [56,57]. Several studies have shown an increase in skin concentrations of calcium, magnesium, aluminum, and phosphorus in hemodialysis patients with pruritus, compared to hemodialysis patients with pruritus and controls $[8,14,34,58-60]$. An increases in the concentration of these molecules causes microprecipitation in the skin leading to pruritus. Few studies show a correlation between serum levels of these ions and pruritus [61-63]. UP also causes hyperparathyroidism, anemia, increased serum histamine levels, and peripheral neuropathy $[12,64]$. Parathyroid hormone increases serum levels of histamine and mast cell proliferation and dramatic improvement in pruritus has been noted after parathyroidectomy [65-67]. However, upon intradermal application of parathormone, no cutaneous reaction or skin biopsy changes was detected [68]. Neither serum phosphate nor other tests of bone and mineral status were determined to be significant predictors of pruritus at any point in time or over time [69]. Atrophy of sebaceous glands is associated with a decreased lipid film surface and is found in ESRD patients; this leads to dehydration of the stratum corneum and promotes pruritus [70-72]. Reduced hydration of the stratum corneum is higher in patients with UP than those without [14].

UVB therapy is beneficial for patients with UP. Possible mechanisms include reduction in skin divalent-ion content, reduction in Vitamin A and retinol content, stabilization of or reduction in number of mast cells, detoxification of undetermined pruritogenic substances, photoactivation of antipruritogenic substances, and changes in the excitability of epidermal nerve endings. Mast cell proliferation, degranulation, and subsequent histamine release plays a role in uremic pruritus [14] (Figure 2). Histamine secretion is evoked by an increased release of SubP. NB-UVB induces apoptosis of dermal mast cells and reduces the release of neuropeptides such as SubP by decreasing epidermal nerve fibers [73-75]. Nitric oxide and IL-2 have also been implicated in the pathogenesis of uremic pruritus, both of which are decreased by NB-UVB [73,76-78]. Schultz et al suggest the response to UVB indicates a deposition of some substance in the skin which is degraded or inactivated by the light. Because uremic patients respond to cholesytramine and phototherapy serves to clear bilirubin in jaundiced premature infants, bile salts were considered to be involved in UP pathogenesis. Individuals with advanced CRF had higher levels of serum total bile acids when compared to controls, and those with pruritus had higher levels of bile acids than those without pruritus [79]. Thus, the intensity of pruritus correlated with bile acid concentration [80]. Certain bile acids also cause cytotoxicity to mastocytes, thereby releasing histamine [81]. 


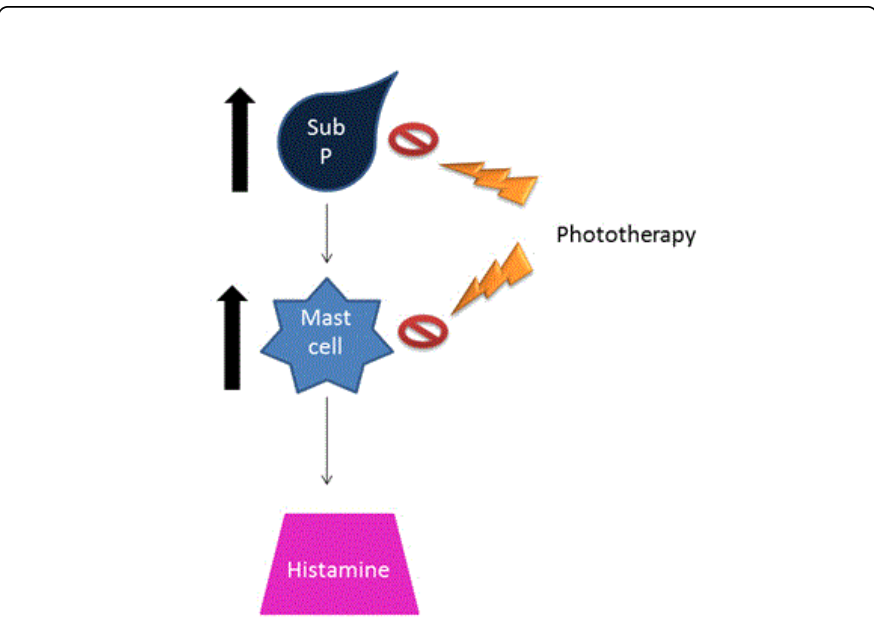

Figure 2: Uremic pruritus.

\section{Efficacy of phototherapy in UP}

Even though NB-UVB is beneficial in decreasing GP \& UP, is less erythemogenic, has a lower pruritogenic potential, and is less carcinogenic than BB-UVB, BB-UVB is the treatment of choice for UP, while UVA is equal to placebo [82,83]. In patients who are not candidates for kidney transplant, BB-UVB is considered to be the treatment of choice by some [14]. While UVB radiation is safe, the risk for skin malignancies and long-term immunosuppression remains controversial in immunocompromised patients due to renal transplant. We did not find any studies on the use of PUVA in UP. Thus, more randomized placebo controlled trials are needed in determining the safest and most efficacious form of phototherapy for decreasing pruritus for patients on dialysis.

\section{Safety of phototherapy}

Phototherapy is a safe form of treatment. When given long-term, PUVA has been associated with increased risk of cutaneous squamous cell carcinoma, but even high-dose exposure does not increase basal cell carcinoma risk [84]. 26 However, all published studies in a comprehensive review of BB-UVB and skin cancer risk, do not demonstrate increased skin cancer risk, with one outlier of genital tumors in men receiving both PUVA and BB-UVB, thus necessitating the contemporary practice of genital shielding [85]. Another retrospective study of 25 years in which 280 psoriatic patients were treated with BB-UVB and coal tar also did not demonstrate an increased skin cancer risk $[86,87]$. A similar study was then conducted on 426 patients with atopic dermatitis and neurodermatitis concluded that the incidence of skin cancer is not significantly increased above the expected incidence for selected populations of the United States when treated with coal tar ointments and ultraviolet light (Goeckerman regimen) [88]. NB-UVB also has an excellent safety profile. In a 2008 study of 4665 patients who received NB-UVB for 17 years had no increase in non-melanoma or melanoma skin cancer [89]. Finally, in a retrospective study of six years, no evidence for increased skin cancer risk was found for either BB- or NB-UVB phototherapy [90].

\section{Limitations}

The conclusions that one can draw by systematically analyzing the current medical literature regarding the use of phototherapy in pruritic disorders are limited due to several factors. Publication bias must be considered in any review article, as trials leading to positive results are more likely to be published [91]. Poor statistical power results from small sample size must also be taken into account. Uncommon adverse effects are often not disclosed or perhaps unrecognized. The variability in parameters of each of the different trials must also be taken into account. Different methods for selecting patients, dosing UV radiation, and assessing the response limit the ability to draw detailed conclusions through a comprehensive review of available studies. Despite these drawbacks, the authors found overwhelming evidence after reviewing the data to conclude that phototherapy is helpful for most types of pruritus.

\section{Conclusion}

We conclude that phototherapy is a beneficial, efficacious, efficient, and safe method of treatment for UP. BB-UVB is the most efficacious for UP, while UVA is equal to placebo. Phototherapy decreases UP through its apoptotic and anti-inflammatory actions and is therefore a useful therapeutic modality. These data conclude there is sufficient evidence to support the use of UV-based treatment for reducing pruritus and its associated manifestations.

\section{References}

1. Zirwas MJ, Seraly MP (2001) Pruritus of unknown origin: a retrospective study. J Am Acad Dermatol 45: 892-896.

2. Ward JR, Bernhard JD (2005) Willan's itch and other causes of pruritus in the elderly. Int J Dermatol 44: 267-273.

3. Aoyama H, Tanaka M, Hara M, Tabata N, Tagami H (1999) Nummular eczema: An addition of senile xerosis and unique cutaneous reactivities to environmental aeroallergens. Dermatology 199: 135-139.

4. Long CC, Marks R (1992) Stratum corneum changes in patients with senile pruritus. J Am Acad Dermatol 27: 560-564.

5. Abdelbaqi-Salhab M, Shalhub S, Morgan MB (2003) A current review of the cutaneous manifestations of renal disease. J Cutan Pathol 30: 527-538.

6. Madiha S, Shahbaz A, Muhammad N, Atif HK (2010) Dermatologic manifestations in patients of renal disease on hemodialysis. Journal of Pakistan Association of Dermatologists 10: 163-168.

7. Lupi O, Rezende L, Zangrando M, Sessim M, Silveira CB, et al. (2011) Cutaneous manifestations in end-stage renal disease. An Bras Dermatol 86: 319-326.

8. Ponticelli C, Bencini PL (1992) Uremic pruritus: a review. Nephron 60: $1-5$.

9. Yosipovitch G, Reis J, Tur E, Sprecher E, Yarnitsky D, Boner G (1995) Sweat secretion, stratum corneum hydration, small nerve function and pruritus in patients with advanced chronic renal failure. Br. J. Dermatol 133: 561-564.

10. Gilchrest BA, Stern RS, Steinman TI, Brown RS, Arndt KA, et al. (1982) Clinical features of pruritus among patients undergoing maintenance hemodialysis. Arch Dermatol 118: 154-156.

11. Masmoudi A, Hajjaji Darouiche M, Ben Salah H, Ben Hmida M, Turki H (2014) Cutaneous abnormalities in patients with end stage renal failure on chronic hemodialysis. A study of 458 patients. J Dermatol Case Rep 8: 86-94.

12. Narita I, Iguchi S, Omori K, Gejyo F (2008) Uremic pruritus in chronic hemodialysis patients. J Nephrol 21: 161-165.

13. Narita I, Alchi B, Omori K, Sato F, Ajiro J, et al. (2006) Etiology and prognostic significance of severe uremic pruritus in chronic hemodialysis patients. Kidney Int 69: 1626-1632. 
14. Szepietowski JC, Schwartz RA (1998) Uremic pruritus. Int J Dermatol 37: 247-253.

15. Greaves MW (2007) Recent advances in pathophysiology and current management of itch. Ann Acad Med Singapore 36: 788-792.

16. Tessari G, Dalle Vedove C, Loschiavo C, Tessitore N, Rugiu C, et al. (2009) The impact of pruritus on the quality of life of patients undergoing dialysis: a single centre cohort study. J Nephrol 22: 241-248.

17. Carmichael AJ, McHugh MI, Martin AM (1991) Renal itch as an indicator of poor outcome. Lancet 337: 1225-1226.

18. Weisshaar E, Matterne U, Mettang T (2009) How do nephrologists in haemodialysis units consider the symptom of itch? Results of a survey in Germany. Nephrol Dial Transplant 24: 1328-1330.

19. Parfrey PS, Vavasour HM, Henry S, Bullock M, Gault MH (1988) Clinical features and severity of nonspecific symptoms in dialysis patients. Nephron 50: 121-128.

20. Pisoni RL, Wikström B, Elder SJ, Akizawa T, Asano Y, et al. (2006) Pruritus in haemodialysis patients: International results from the Dialysis Outcomes and Practice Patterns Study (DOPPS). Nephrol Dial Transplant 21: 3495-3505.

21. Mathur VS, Lindberg J, Germain M, Block G, Tumlin J, et al. (2010) A longitudinal study of uremic pruritus in hemodialysis patients. Clin J Am Soc Nephrol 5: 1410-1419.

22. Ståhle-Bäckdahl M, Hägermark O, Lins LE (1988) The sensitivity of uremic and normal human skin to histamine. Acta Derm Venereol 68: 230-235.

23. Attia EA, Hassan AA (2014) Uremic pruritus pathogenesis, revisited. Arab J Nephrol Transplant 7: 91-99.

24. Mettang T, Kremer AE (2015) Uremic pruritus. Kidney Int 87: 685-691.

25. Veith W, Deleo V, Silverberg N (2011) Medical phototherapy in childhood skin diseases. Minerva Pediatr 63: 327-333.

26. Stern RS; PUVA Follow-Up Study (2012) The risk of squamous cell and basal cell cancer associated with psoralen and ultraviolet A therapy: a 30year prospective study. J Am Acad Dermatol 66: 553-562.

27. Samson Yashar S, Gielczyk R, Scherschun L, Lim HW (2003) Narrowband ultraviolet $\mathrm{B}$ treatment for vitiligo, pruritus, and inflammatory dermatoses. Photodermatol Photoimmunol Photomed 19: 164-168.

28. Seckin D, Demircay Z, Akin O (2007) Generalized pruritus treated with narrowband UVB. Int J Dermatol 46: 367-370.

29. Ada S, SeÃ§kin D, BudakoÄŸlu I, Ozdemir FN (2005) Treatment of uremic pruritus with narrowband ultraviolet B phototherapy: an open pilot study. J Am Acad Dermatol 53: 149-151.

30. Balaskas EV, Bamihas GI, Karamouzis M, Voyiatzis G, Tourkantonis A (1998) Histamine and serotonin in uremic pruritus: effect of ondansetron in CAPD-pruritic patients. Nephron 78: 395-402.

31. Ko MJ, Yang JY, Wu HY, Hu FC, Chen SI, et al. (2011) Narrowband ultraviolet $\mathrm{B}$ phototherapy for patients with refractory uraemic pruritus: a randomized controlled trial. Br J Dermatol 165: 633-639.

32. Gilchrest BA, Rowe JW, Brown RS, Steinman TI, Arndt KA (1977) Relief of uremic pruritus with ultraviolet phototherapy. N Engl J Med 297: 136-138.

33. Taylor R, Taylor AE, Diffey BL, Hindson TC (1983) A placebo-controlled trial of UV-A phototherapy for the treatment of uraemic pruritus. Nephron 33: 14-16.

34. Blachley JD, Blankenship DM, Menter A, Parker TF 3rd, Knochel JP (1985) Uremic pruritus: skin divalent ion content and response to ultraviolet phototherapy. Am J Kidney Dis 5: 237-241.

35. Simpson NB, Davison AM (1981) Ultraviolet phototherapy for uraemic pruritus. Lancet 1: 781.

36. Berne B, Vahlquist A, Fischer T, Danielson BG, Berne C (1984) UV treatment of uraemic pruritus reduces the vitamin A content of the skin. Eur J Clin Invest 14: 203-206.

37. Gilchrest BA, Rowe JW, Brown RS, Steinman TI, Arndt KA (1979) Ultraviolet phototherapy of uremic pruritus. Long-term results and possible mechanism of action. Ann Intern Med 91: 17-21.
38. Schultz BC, Roenigk HH Jr (1980) Uremic pruritus treated with ultraviolet light. JAMA 243: 1836-1837.

39. Cohen EP, Russell TJ, Garancis JC (1992) Mast cells and calcium in severe uremic itching. Am J Med Sci 303: 360-365.

40. Hsu MM, Yang CC (2003) Uraemic pruritus responsive to broadband ultraviolet (UV) B therapy does not readily respond to narrowband UVB therapy. Br J Dermatol 149: 888-889.

41. Bernhard JD (2005) Itch and pruritus: what are they, and how should itches be classified? Dermatol Ther 18: 288-291.

42. Andrew D, Craig AD (2001) Spinothalamic lamina I neurons selectively sensitive to histamine: a central neural pathway for itch. Nat Neurosci 4: 72-77.

43. Schmelz M, Schmidt R, Bickel A, Handwerker HO, Torebjörk HE (1997) Specific C-receptors for itch in human skin. J Neurosci 17: 8003-8008.

44. Denda M, Nakatani M, Ikeyama K, Tsutsumi M, Denda S (2007) Epidermal keratinocytes as the forefront of the sensory system. Exp Dermatol 16: 157-161.

45. Paus R, Schmelz M, Bíró T, Steinhoff M (2006) Frontiers in pruritus research: scratching the brain for more effective itch therapy. J Clin Invest 116: 1174-1186.

46. Inoue K, Koizumi S, Fuziwara S, Denda S, Inoue K, et al. (2002) Functional vanilloid receptors in cultured normal human epidermal keratinocytes. Biochem Biophys Res Commun 291: 124-129.

47. Heymann WR (2006) Itch. J Am Acad Dermatol 54: 705-706.

48. Denman ST (1986) A review of pruritus. J Am Acad Dermatol 14: 375-392.

49. Steinhoff M, Ständer S, Seeliger S, Ansel JC, Schmelz M, et al. (2003) Modern aspects of cutaneous neurogenic inflammation. Arch Dermatol 139: $1479-1488$

50. Steinhoff M, Vergnolle N, Young SH, Tognetto M, Amadesi S, et al. (2000) Agonists of proteinase-activated receptor 2 induce inflammation by a neurogenic mechanism. Nat Med 6: 151-158.

51. Dugas-Breit S, Schöpf P, Dugas M, Schiffl H, Ruëff F, et al. (2005) Baseline serum levels of mast cell tryptase are raised in hemodialysis patients and associated with severity of pruritus. J Dtsch Dermatol Ges 3: 343-347.

52. Valet M, Pfab F, Sprenger T, Wöller A, Zimmer C, et al. (2008) Cerebral processing of histamine-induced itch using short-term alternating temperature modulation--an FMRI study. J Invest Dermatol 128: 426-433.

53. MELZACK R, SCHECTER B (1965) ITCH AND VIBRATION. Science 147: 1047-1048.

54. Ständer S, Schmelz M (2006) Chronic itch and pain--similarities and differences. Eur J Pain 10: 473-478.

55. Drzezga A, Darsow U, Treede RD, Siebner H, Frisch M, et al. (2001) Central activation by histamine-induced itch: analogies to pain processing: a correlational analysis of $\mathrm{O}-15 \mathrm{H} 2 \mathrm{O}$ positron emission tomography studies. Pain 92: 295-305.

56. Fantini F, Baraldi A, Sevignani C, Spattini A, Pincelli C, et al. (1992) Cutaneous innervation in chronic renal failure patients. An immunohistochemical study. Acta Derm Venereol 72: 102-105.

57. Kimmel M, Alscher DM, Dunst R, Braun N, Machleidt C, et al. (2006) The role of micro-inflammation in the pathogenesis of uraemic pruritus in haemodialysis patients. Nephrol Dial Transplant 21: 749-755.

58. Rosen T (1979) Uremic pruritus: a review. Cutis 23: 790-792.

59. Cho YL, Liu HN, Huang TP, Tarng DC (1997) Uremic pruritus: roles of parathyroid hormone and substance P. J Am Acad Dermatol 36: 538-543.

60. Noordzij M, Boeschoten EW, Bos WJ, Dekker FW, Bossuyt PM, et al. (2007) Disturbed mineral metabolism is associated with muscle and skin complaints in a prospective cohort of dialysis patients. Nephrol Dial Transplant 22: 2944-2949.

61. Akhyani M, Ganji MR, Samadi N, Khamesan B, Daneshpazhooh M (2005) Pruritus in hemodialysis patients. BMC Dermatol 5: 7. 
Citation: Thakur A, Chaudhari S, Chaudhari P, Thakur M (2015) Phototherapy as a Treatment for Uremic Pruritus - A Review. Gen Med (Los

62. Carmichael AJ, McHugh MM, Martin AM, Farrow M (1988) Serological markers of renal itch in patients receiving long term haemodialysis. Br Med J (Clin Res Ed) 296: 1575.

63. Dar NR, Akhter A (2006) Clinical characteristics of uremic pruritus in patients undergoing haemodialysis. J Coll Physicians Surg Pak 16: 94-96.

64. Patel TS, Freedman BI, Yosipovitch G (2007) An update on pruritus associated with CKD. Am. J. Kidney Dis 50: 11-20.

65. Neiman RS, Bischel MD, Lukes RJ (1972) Uraemia and mast-cell proliferation. Lancet 1: 959.

66. Hampers CL, Katz AI, Wilson RE, Merrill JP (1968) Disappearance of "uremic" itching after subtotal parathyroidectomy. N Engl J Med 279: 695-697.

67. Massry SG, Popovtzer MM, Coburn JW, Makoff DL, Maxwell MH, et al. (1968) Intractable pruritus as a manifestation of secondary hyperparathyroidism in uremia. Disappearance of itching after subtotal parathyroidectomy. N Engl J Med 279: 697-700.

68. Ståhle-Bäckdahl M, Hägermark $\mathrm{O}$, Lins LE, Törring $\mathrm{O}$, Hilliges $\mathrm{M}$, et al. (1989) Experimental and immunohistochemical studies on the possible role of parathyroid hormone in uraemic pruritus. J Intern Med 225: 411-415.

69. Shirazian S, Kline M, Sakhiya V, Schanler M, Moledina D, et al. (2013) Longitudinal predictors of uremic pruritus. J Ren Nutr 23: 428-431.

70. Kato A, Hamada M, Maruyama T, Maruyama Y, Hishida A (2000) Pruritus and hydration state of stratum corneum in hemodialysis patients. Am J Nephrol 20: 437-442.

71. Deleixhe-Mauhin F, Piérard-Franchimont C, Krezinski JM, Rorive G Piérard GE (1993) Biometrological evaluation of the stratum corneum texture in patients under maintenance hemodialysis. Nephron 64 : 110-113.

72. Ostlere LS, Taylor C, Baillod R, Wright S (1994) Relationship between pruritus, transepidermal water loss, and biochemical markers of renal itch in haemodialysis patients. Nephrol. Dial. Transplant 9: 1302-1304.

73. Urbonas A, Schwartz RA, Szepietowski JC (2001) Uremic pruritus--an update. Am J Nephrol 21: 343-350.

74. Szepietowski JC, Morita A, Tsuji T (2002) Ultraviolet B induces mast cell apoptosis: a hypothetical mechanism of ultraviolet B treatment for uraemic pruritus. Med Hypotheses 58: 167-170.

75. Wallengren J, Sundler F (2004) Phototherapy reduces the number of epidermal and CGRP-positive dermal nerve fibres. Acta Derm Venereol 84: 111-115.

76. Mettang T, Pauli-Magnus C (2000) The pathophysiological puzzle of uremic pruritus--insights and speculations from therapeutic and epidemiological studies. Perit Dial Int 20: 493-494.
77. Yamaoka J, Sasaki M, Miyachi Y (2000) Ultraviolet B radiation downregulates inducible nitric oxide synthase expression induced by interferon-gamma or tumor necrosis factor-alpha in murine keratinocyte Pam 212 cells. Arch Dermatol Res 292: 312-319.

78. Walters IB, Ozawa M, Cardinale I, Gilleaudeau P, Trepicchio WL, et al. (2003) Narrowband (312-nm) UV-B suppresses interferon gamma and interleukin (IL) 12 and increases IL-4 transcripts: differential regulation of cytokines at the single-cell level. Arch Dermatol 139: 155-161.

79. Silverberg DS, Iaina A, Reisin E, Rotzak R, Eliahou HE (1977) Cholestyramine in uraemic pruritus. Br Med J 1: 752-753.

80. Borgeat A, Stirnemann HR (1999) Ondansetron is effective to treat spinal or epidural morphine-induced pruritus. Anesthesiology 90: 432-436.

81. Quist RG, Ton-Nu HT, Lillienau J, Hofmann AF, Barrett KE (1991) Activation of mast cells by bile acids. Gastroenterology 101: 446-456.

82. Larsen J, Haedersdal M, Wulf HC (1994) Scratching and ultraviolet irradiation: an experimental animal model. Photodermatol Photoimmunol Photomed 10: 38-41.

83. Zanolli M (2003) Phototherapy treatment of psoriasis today. J Am Acad Dermatol 49: S78-86.

84. Pathirana D, Ormerod AD, Saiag P, Smith C, Spuls PI, et al. (2009) European S3-guidelines on the systemic treatment of psoriasis vulgaris. J Eur Acad Dermatol Venereol 23 Suppl 2: 1-70.

85. Lee E, Koo J, Berger T (2005) UVB phototherapy and skin cancer risk: a review of the literature. Int J Dermatol 44: 355-360.

86. Lebwohl M (2002) Should we switch from combination UVA/UVB phototherapy units to narrowband UVB? Photodermatol. Photoimmunol. Photomed 18: 44-46.

87. Pittelkow MR, Perry HO, Muller SA, Maughan WZ, O'Brien PC (1981) Skin cancer in patients with psoriasis treated with coal tar. A 25-year follow-up study. Arch Dermatol 117: 465-468.

88. Maughan WZ, Muller SA, Perry HO, Pittelkow MR, O'Brien PC (1980) Incidence of skin cancers in patients with atopic dermatitis treated with ocal tar. A 25-year follow-up study. J Am Acad Dermatol 3: 612-615.

89. Hearn RM, Kerr AC, Rahim KF, Ferguson J, Dawe RS (2008) Incidence of skin cancers in 3867 patients treated with narrow-band ultraviolet B phototherapy. Br J Dermatol 159: 931-935.

90. Weischer M, Blum A, Eberhard F, Röcken M, Berneburg M (2004) No evidence for increased skin cancer risk in psoriasis patients treated with broadband or narrowband UVB phototherapy: a first retrospective study. Acta Derm Venereol 84: 370-374.

91. Ladhani S (1997) The need for evidence-based management of skin diseases. Int J Dermatol 36: 17-22. 